\title{
Gender Differences in Equity Crowdfunding
}

\author{
Emôke-Ágnes Horvát \\ School of Communication \\ Northwestern University \\ a-horvat@northwestern.edu
}

\author{
Theodore Papamarkou \\ School of Mathematics and Statistics \\ University of Glasgow \\ theodore.papamarkou@glasgow.ac.uk
}

\begin{abstract}
Online peer-to-peer investment platforms are increasingly popular venues for entrepreneurs and investors to engage in financial transactions without the involvement of banks and loan managers. Despite their purported transparency and lack of bias, it is unclear whether social inequalities present in traditional capital markets transfer to these platforms as well, impeding their hoped revolutionary potential. In this paper we analyze nearly four years' worth of data from one of the leading UK-based equity crowdfunding platforms. Specifically, we investigate gender-related differences in patterns of entrepreneurship, investment, and success. In agreement with offline trends, men have more activity on the platform. Yet, women entrepreneurs benefit of higher success rates in fundraising, a finding that mimics trends seen on some rewardsbased crowdfunding platforms. Surprisingly, we also find that female investors tend to choose campaigns that have lower success rates. Our findings contribute to a better understanding of gender-related discrepancies in success on the online capital market and point to differences in activity that are key factors in the apparent patterns of gender inequality.
\end{abstract}

\section{Introduction}

Existing finance models in capital markets have been shown to disadvantage female entrepreneurs and investors (Blanchflower, Levine, and Zimmerman 2003; Alesina, Lotti, and Mistrulli 2013; Dorfleitner et al. 2013). In 2007, 86\% of angel investors were men and less than $10 \%$ of all companies that received venture capital funding were led by women. Research has identified several mechanisms through which this inequality is perpetuated, ranging from statistical and taste-based discrimination (Barasinska and Schaefer 2014) to homophily (Greenberg and Mollick 2016) and womens own beliefs about their aptitudes and value on the labor market (Gorbatai and Nelson 2015).

Crowdfunding is touted to be a transparent and disintermediated internet-based market place that might democratize access to capital for minority groups and eventually neutralize gender bias. In crowdfunding, millions of independent individuals (the crowd) come together to provide funds to people and campaigns that capture their imagination and/or financial interests. This model is a reflection of

Copyright (C) 2017, Association for the Advancement of Artificial Intelligence (www.aaai.org). All rights reserved. a larger wave of 'commons' trends: Phenomena like Citizen Science (Cooper et al. 2010), open source software (Weber 2004), online activism and public governance (McCaughey and Ayers 2003), as well as cooperatively-authored online encyclopedia (Bryant, Forte, and Bruckman 2005) are frequently discussed for their purported superior outcomes and flexibility as compared to tightly controlled single-source systems. These movements are backed up by evidence suggesting that crowds are more agile, use diverse perspectives to act innovatively, and consequently provide broader solutions (van Knippenberg, Dreu, and Homan 2004; Page 2007; Jeppesen and Lakhani 2010; Sauermann and Franzoni 2015).

In this paper we ask whether the wisdom of crowds that emerges in crowdfunding can contribute to equalizing the playing field between the genders. So far, it has been shown empirically that women's participation rate in crowdfunding is considerably higher than in traditional entrepreneurship and investing. See, for instance, the study of Marom et al. about the rewards-based crowdfunding platform Kickstarter (Marom, Robb, and Sade 2016). Furthermore, women enjoy higher rates of success in funding their campaigns, an outcome that has become apparent on platforms such as the rewards-based crowdfunding site Indiegogo (Gorbatai and Nelson 2015), the microfinance site Kiva, and the oldest P2P lending platform in the U.S. called Prosper (Ravina 2012; Barasinska and Schaefer 2014). While these are promising results for small businesses, as of now it is unclear whether gender-related differences are also dampened in the case of equity investments. These involve typically higher amounts of capital and often the desire of funders to intimately know the entrepreneur and her business (Cumming and Dai 2010). Equity crowdfunding has appeared later than other forms of crowdfunding, but is nevertheless catching up in popularity. As a matter of fact, it is expected that equity crowdfunding platforms will challenge venture capitalists and business angel financiers in the near future (Vulkan, Astebro, and Sierra 2016). Our work contributes to the nascent literature on this promising form of crowdfunding.

We operationalize our analysis using data from the oldest and one of the two leading equity crowdfunding sites in the UK. The data set was kindly shared with us by the company and contains the complete record of their activity from the 
inception in 2012 until early 2016. In this time period, the company has promoted requests for more than $£ 117.4$ million and enabled transactions that total to $£ 57.7$ million. At the time of writing, the site continues to expand its client base and features.

The paper is organized as follows: First, we review related literature on crowdfunding in general and equity crowdfunding in specific. We also survey existing research on gender divides in raising capital and investing, both offline and online. Next, we provide details about the used data and methodological approaches. We then summarize our findings that $(i)$ position the platform on the landscape of other crowdfunding settings in terms of gender differences, (ii) establish the effect of gender on campaign outcome, and (iii) study the flow of capital in the context of the emerging entrepreneur-investor network. We conclude the paper with a discussion about the limitations of our data set and results.

\section{Related Work}

Extensive work on crowdfunding focuses on predicting campaign success. Inferring outcomes is of interest for entrepreneurs, investors, crowdfunding platforms, and policymakers alike. Existing research investigates the predictive power of entrepreneur and campaign characteristics. Predictors range from objective indicators like credit score (Iyer et al. 2009; Ceyhan, Shi, and Leskovec 2011), to rather unexpected variables such as social capital (Freedman and Jin 2008; Greenberg et al. 2013; Mollick 2014), appearance (Duarte, Siegel, and Young 2012; Ravina 2012), and language of campaign descriptions (Althoff, DanescuNiculescu-Mizil, and Jurafsky 2014; Gorbatai and Nelson 2015). Whereas these pioneering works have shed light on important factors associated with success, there is nevertheless a need for a better understanding of gender-related differences in campaign outcome.

The question is especially relevant since empirical evidence shows that women business owners launch their firms with significantly less capital than men (Coleman and Robb 2009). In general, women prefer internal rather than external sources of equity capital (Chaganti, DeCarolis, and Deeds 1995) to the extent that between 1953 and 1998 less than five percent of total venture capital funding went to firms owned by women (Brush et al. 2008).

Yet, in some online fund-raising settings, women tend to be systematically more successful than men. One possible explanation is the language divide that becomes apparent in project pitches and benefits typically female communication styles (Gorbatai and Nelson 2015). A more structural argument is based on notions of homophily. First, there is evidence of gender-based choice homophily that stems from the similarity between individuals. E.g., according to the findings of Marom et al., more than $40 \%$ of Kickstarter campaigns that women invest in have female leads. In comparison, only $23 \%$ of campaigns that men invest in are led by women (Marom, Robb, and Sade 2016). Second, perceptions of shared structural barriers that stem from a common social identity might lead to activist choice homophily, which can clarify why women are more likely to succeed at crowdfunding than men despite being less represented (Greenberg and Mollick 2016).

Research about equity crowdfunding is in its infancy, mostly due to the fact that these platforms faced regulatory hurdles before being able to start operation (Ahlers et al. 2015; Vismara 2016; Vulkan, Astebro, and Sierra 2016). Equity crowdfunding differs from microfinance-, rewards- and loan-based crowdfunding in multiple ways, among which most notably (i) campaign targets approach the size of first round investments for venture capitals, and (ii) funders have a clear goal to obtain significant monetary rewards for their investments (Vulkan, Astebro, and Sierra 2016). This new setting characterizes thus decision-making under extreme risk relative to the more common forms of crowdfunding that have been at the center of prior research. Moreover, the uncertainty associated with equity investing is compounded by limited investor expertise and available resources in evaluating the moral hazard problems inherent in equity investments (Gompers and Lerner 2004; Mohammadi and Shafi 2017).

In the little existing research on equity crowdfunding, to the best of our knowledge, there is only one study that looks at gender differences. In the immediate past, Mohammadi and Shafi focused on investment behavior when analyzing a sample of 40 successful equity campaigns from a Swedish equity crowdfunding platform called FundedByMe and found that female investors are more risk averse than their male counterparts and tend to invest in campaigns in which the proportion of male investors is higher (Mohammadi and Shafi 2017). Along these lines, our paper investigates entrepreneurial and investment behavior using a crossdisciplinary approach and makes connections between gender and campaign outcome for the first time in the case of equity crowdfunding.

More broadly, gender inequality is a wide-spread, welldocumented phenomenon in the offline labor market, at home, and in cultural production (Blau and Kahn 2000; Bianchi, Robinson, and Milkie 2006; Mandel 2013; Lutter 2015). Literature on the gender gap in Internet skills and usage patterns is growing (Hargittai 2010), yet we know little about how the digital divide transfers to crowdsourcing platforms and how this might propagate and potentially amplify offline inequalities. Although there is evidence for lower female contribution rates for instance on peer production platforms (Robles et al. 2014; Vasilescu et al. 2015; Hargittai and Shaw 2015) and in online freelance communities (Wachs et al. 2017), quantifying the implications of imbalanced gender composition remains challenging. Equity crowdfunding is a setting that enables direct measurements of performance. Our study uses this feature to contribute to the general open question about the effect of gender imbalance in participation on success rates in crowdsourcing.

\section{Data and Descriptives}

Data The site we study is a UK-based leading equity crowdfunding platform that provides capital to entrepreneurs to launch new businesses. Through the site, investors from the greater European area provide capital in return for an equity in a new product, business or service. Our 
preprocessed sample consists of 727 campaigns launched between May 22, 2012 and January 24, 2016. In this sample, 17,861 unique investors contributed to campaigns of 576 unique entrepreneurs. Out of these, 152 individuals had a dual role meaning that they were both entrepreneurs and investors on someone else's campaign. Campaigns raise funds from the investor crowd gathered on the platform to infuse private capital in new ventures. During the time frame under consideration, $33.4 \%$ of the campaigns with known outcome managed to raise their targets.

Elicitation of gender Since the platform doesn't record the gender of their users, we extract this information from the investors' and entrepreneurs' first names using the U.S. baby name database (soc). This is an increasingly popular method (Liu and Ruths 2013; Karimi et al. 2016; Wachs et al. 2017). Every name in the U.S. baby name database is accompanied by the number of its occurrences among male and female babies. We deduce the gender of each investor and entrepreneur in the data set by selecting the gender with the highest absolute frequency in the U.S. baby name database. With this automatic method we are able to classify $92.6 \%$ of the users as male or female. Our final dataset contains 12,863 male and 3,945 female users.

Determination of campaign outcome The platform has an all or nothing policy meaning that only campaigns that manage to raise their target receive capital. The funds redeemed on the site can be higher than the target amount. When assessing the success of a campaign, we focus on 'accepted' and 'processed' investments and consider those campaigns to be successful that have met their investment target. Our binary outcome variable is thus defined as

$$
y= \begin{cases}1, & \text { if } \sum_{i} a_{i} / A \geq 1 \\ 0, & \text { otherwise }\end{cases}
$$

where $a_{i}$ denotes the $i^{\text {th }}$ investment in a campaign with target amount $A$. The choice of a binary outcome variable is motivated by the shape of the histogram shown in Figure 1. Looking at the percentage of the target amount that was actually raised by individual campaigns, we see that typical campaigns either raise a small fraction of their target amount (hence the first peak in the low-percentage area) or raise their exact target amount or slightly more (hence the second peak at and after $100 \%$ ). This strong bimodal shape points to the two predominant cases and justifies the simplification we make when using a binary success variable.

Extraction and selection of covariates There are several observed characteristics of entrepreneurial teams, campaigns, and investor groups that we hypothesize to be connected to successful campaign outcome:

- Gender of entrepreneur is a binary indicator that refers to the team-leader as the key individual behind the proposed equity crowdfunding campaign. This crucial covariate enables us to connect our findings to mounting

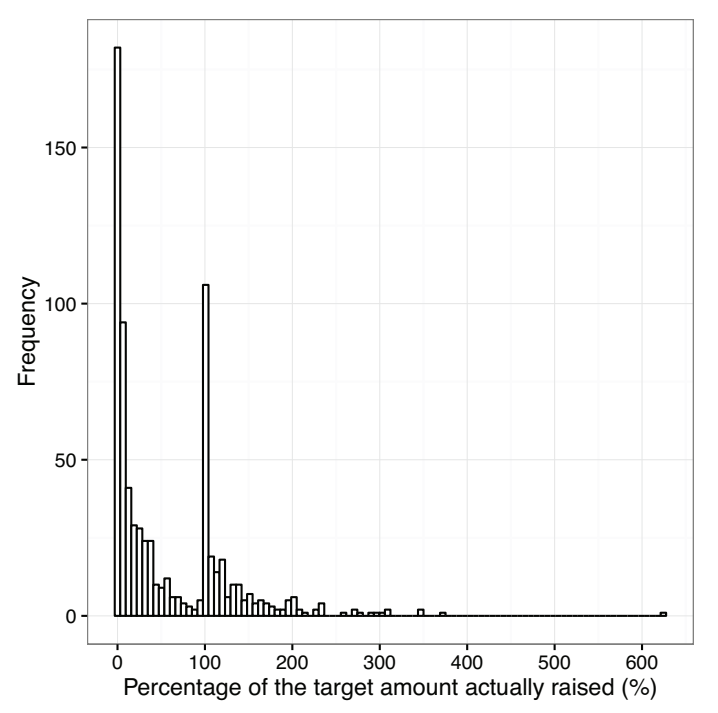

Figure 1: Histogram showing the frequency of campaigns that raise given percentages of their target amounts. The two peaks at $0 \%$ and $100 \%$ indicate two predominant cases that motivated the binary outcome variable we use throughout the study

evidence about female-led ventures that are disadvantaged in the capital market (Blanchflower, Levine, and Zimmerman 2003; Alesina, Lotti, and Mistrulli 2013; Dorfleitner et al. 2013; Brooks et al. 2014; Kanze et al. 2017).

- Platform familiarity pertains to the activity on the site and is quantified by the total number of successful and failed campaigns launched by the lead entrepreneur. Looking at the history of an entrepreneur on the platform provides a good proxy for the familiarity with platform practices. Moreover, literature on start-ups shows that serial entrepreneurs perform better than novices (Zhang 2011).

- Team size is the number of entrepreneurs listed on the site to make up the group of executives behind the campaign. Smaller teams might be riskier since they might be more recent and have had less time to accumulate resources and experience. Aside of team size, the platform doesn't collect further information such as gender composition about the group of entrepreneurs.

- Equity offering (\%) of a campaign is a signal of riskiness in traditional investment settings (Leland and Pyle 1977). It has been shown recently in the setting of equity crowdfunding that high equity is perceived as a negative signal most probably due to the suggested overvalued shares and higher risk (Mohammadi and Shafi 2017).

- Target amount is the valuation of the campaign in British pounds $(£)$ and is expected to be negatively associated with fund-raising success (Uzzi 1999). Given the skewed distribution of the requested amounts, this covariate is logged.

- Investor gender (\%) denotes the proportion of investors 
who are female to the total count of all investors of a campaign. The share of female investors might relate to the overall attractiveness of a campaign for women due to shared preferences borne out of gender similarity.

- To minimize the barriers to entry, the site does not require that investors acquire external certificates. Instead, it offers the possibility to indicate on a voluntary basis wealthy users (i.e., high net worth individuals) and experienced investors (i.e., sophisticated investors). A truthful assignment of these labels can be expected to correlate with better investment decisions and potentially a leading role in setting examples for novice or less certain investors. During the time frame of our sample, the site counted 2,288 self-proclaimed high net worth individuals and 1,305 sophisticated investors. Our corresponding covariates compute the percentage of high net worth individuals and sophisticated investors per campaign. Note that this self-reported data might be linked to gender identity and confidence. Indeed, we see that $6.8 \%$ women vs. $9 \%$ men consider themselves to be sophisticated investors, and $8.3 \%$ women vs. $16.6 \%$ men are high net worth individuals.

- UK investors (\%) Since only about $20 \%$ of the investments come from outside the UK and some of the qualifying UK-based campaigns have certain tax-benefits, another feature is the percentage of investors contributing to the campaign who are from the UK.

Table 1 provides the mean, standard deviation and correlation between the above covariates. One covariate is binary (entrepreneur gender), two are integer-valued (entrepreneur experience and team size), five represent percentages (equity offering, female-, sophisticated-, high net worth- and UK-based investors), and the target amount is continuous. All covariates are highly dispersed as seen from their means and respective standard deviations. The high variability in the data set is partly explained by the relatively moderate sample size and the associated sparsity of transactions. The correlation matrix among the nine covariates exhibits low pairwise correlations. Thus, there are no obvious associations between potential predictors of campaign success.

Creation of the entrepreneur-investor network User activity on the site can be mapped to a network that traces over time the flow of capital between individuals. The network-based approach enables considering structural dependencies that arise due to the available resources and market competition. Structural dependencies are not incorporated in classical regression models despite the fact that they have the potential to give a more accurate account of how different individual and contextual factors contribute to the probability of an investment. The key factor of interest in this case is gender-homophily, which means that connections are more likely to be formed between users of the same gender.

To study homophily, we model the entrepreneur-investor network with the graph $G=(V, E, \Omega, T)$ which denotes a directed weighted temporal graph whose nodes $v, w \in V$ represent users and directed edges $(v \rightarrow w) \in E$ represent investments of a certain amount $a \in \Omega$ at a specific time $t \in T$. Individuals on the site have attributes that relate to their gender and activity on the platform. They also have multiple roles $r \in\{I, E, I E\}$ : investor $(I)$, entrepreneur $(E)$, or both $(I E)$, which is inherently coded in the network structure. Accordingly, nodes with $r=I$ have only outgoing edges, nodes with $r=E$ have only incoming edges, while nodes with $r=I E$ have both outgoing and incoming edges, which is a structural detail that gives rise to different degree distributions (see Figure 2). The graph admits (i) self-loops $e=(v, v)$ that arise whenever an entrepreneur invests in her own campaign, and (ii) multi-edges between the same pair of entrepreneur and investor $e_{1}=e_{2}=(v, w)$. Multi-edges differ in time stamp and/or amount of transaction: $t_{1} \neq t_{2}$ and/or $a_{1} \neq a_{2}$.

Summaries of the entrepreneur-investor network The most complete static snapshot of the entrepreneur-investor network aggregates all successful and unsuccessful transactions over the entire time period of our sample. With 18,153 nodes and 59,322 edges, it is very sparse $(\delta<0.01)$. The network has a quasi-bipartite structure: The majority of the users are either investors or entrepreneurs, and the transactions occur typically between the two roles. Self-loops are possible, but rather a rarity $(n=533)$. Multiple edges are far more common ( $m=12,372)$ and given the low reciprocity of connections $(\rho<0.01)$, they indicate that repeated transactions cannot be explained based on mutual help. An alternative reason might be related to trust that arises from positive experience with an entrepreneur as hypothesized on a lending crowdfunding platform (Horvát, Uparna, and Uzzi 2015).

The right-skewed degree distributions ${ }^{1}$ displayed in Figure 2 indicate a strong heterogeneity in terms of entrepreneur and investor involvement. Similarly to various online production systems, the minority of the users are accountable for a large portion of the activity on the platform (Matei and Britt ). This mimics offline inequalities that ultimately give rise to 'elites'.

\section{Findings}

We conduct our study along three lines of investigation. First, we evaluate in the context of the studied platform some of the most striking gender-related differences that existing research has identified to be most prominent both off- and online. Second, we build models that expose the effect of entrepreneur and investor gender on campaign outcome net of various controls. Third, we use a network-based approach to explore the role of gender-homophily, which has been assumed to contribute to the the gender inequalities we highlight in the following.

Gender patterns in entrepreneurship and investment In terms of participation, $14.8 \%$ of the investors and $13.7 \%$

\footnotetext{
${ }^{1}$ The degree of a node is the number of connections it has to other nodes. The degree distribution of a network quantifies the probability of these degrees across the entire network (Kolaczyk 2009).
} 


\begin{tabular}{|c|c|c|c|c|c|c|c|c|c|c|}
\hline & Mean & S.D. & (1) & $(2)$ & (3) & (4) & (5) & (6) & $(7)$ & $(8)$ \\
\hline (1) Female entrepreneur & 1.14 & 0.34 & - & & & & & & & \\
\hline (2) Entrepreneur experience & 1.33 & 0.83 & 0.01 & - & & & & & & \\
\hline (3) Team size & 3.09 & 1.93 & 0.09 & 0.10 & - & & & & & \\
\hline (4) Equity offering (\%) & 12.32 & 8.59 & 0.01 & -0.22 & -0.19 & - & & & & \\
\hline (5) Target amount ${ }^{\dagger}$ & 1.62 & 3.19 & -0.01 & 0.02 & 0.35 & 0.15 & - & & & \\
\hline (6) Female investors (\%) & 0.16 & 0.15 & 0.18 & -0.12 & 0.10 & 0.08 & 0.14 & - & & \\
\hline (7) Sophisticated investors (\%) & 0.07 & 0.09 & -0.04 & 0.11 & 0.12 & -0.11 & 0.06 & 0.01 & - & \\
\hline (8) High net worth investors (\%) & 0.16 & 0.15 & -0.01 & 0.03 & -0.04 & 0.07 & 0.01 & -0.19 & -0.03 & - \\
\hline (9) UK investors (\%) & 0.84 & 0.19 & 0.07 & 0.01 & -0.24 & 0.20 & -0.03 & -0.02 & -0.13 & 0.20 \\
\hline
\end{tabular}

$\dagger$ Multiply by $10^{5}$ to acquire mean and standard deviation of target amount in GBP $(£)$.

Table 1: Basic statistics and pairwise correlation between entrepreneur- and investor-related covariates aggregated at the campaign-level $(N=680)$. Covariates of special interest are gender of entrepreneur $(1)$ and percentage of female investors (6)

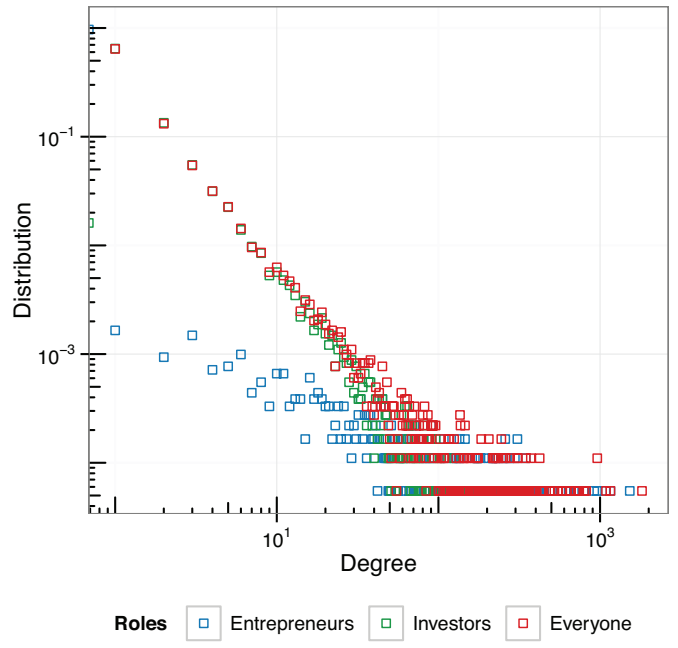

Figure 2: Degree distributions shown on a log-log scale for entrepreneurs, investors and the entire network ('everyone'). The entrepreneur-investor network tracks the flow of capital and is quasi-bipartite, meaning that most of the edges connect entrepreneurs to investors. There are, however, users who at some point during the considered time frame have assumed both roles

of the entrepreneurs are female. These numbers position the equity crowdfunding platform between traditional capital markets and rewards-based crowdfunding and attest to the still far lower inclusion of women than expected based on their base rates in the population.

Given the significant discrepancies in the asking- and giving amounts between the genders in other financial settings as documented in the literature, our first exploratory questions are: Do women entrepreneurs ask for less money? Furthermore, do they end up obtaining less capital? Figure 3 shows the distribution of target and raised amounts for men and women entrepreneurs. Although there is slightly more heterogeneity in the asking amounts and received funds of men, there is no statistically significant difference between men and women as indicated by a two-sided Kolmogorov-
Smirnoff test $(p>.1)$. As mentioned before, entrepreneurs on the site represent a team of individuals. Team size, however, is also not significantly different on this sample size for male- and female-led entrepreneurs (two-sided Kolmogorov-Smirnoff test: $p>.1$ ).

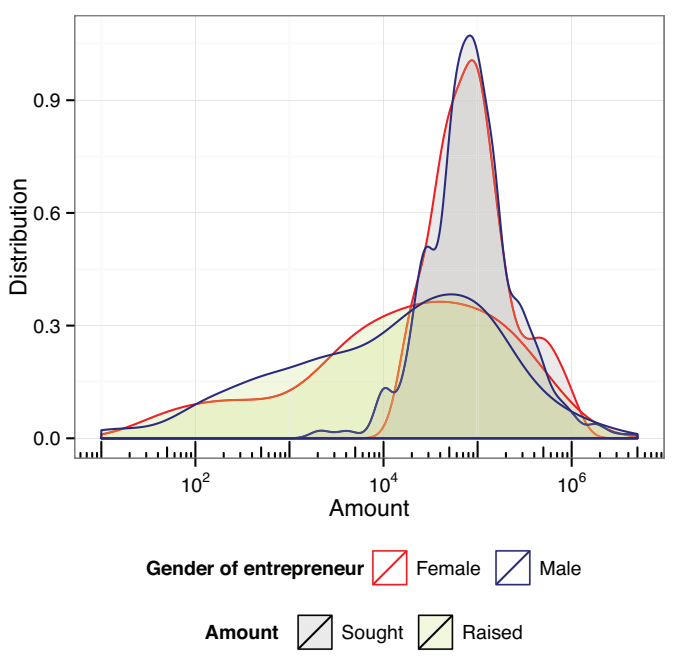

Figure 3: Comparison between target- and raised amount shown for male and female entrepreneurs, respectively. The plotted data contains information on both successful and unsuccessful projects. Accordingly, there is no statistically significant difference between the amounts asked/received by men and women

At a first glance female entrepreneurs and investors have different success rates than their male colleagues. On the entrepreneurial side, $38.7 \%$ of the female-led and $33.4 \%$ of the male-led campaigns reach their target. On the investment side, $66.4 \%$ of women's investments and $73 \%$ of men's investments are going to funded campaigns indicating that men are more successful investors.

Campaign success and gender Initially, we fit a binomial logistic regression model to the data using the campaign outcome defined in Equation (1) and the nine available covari- 
ates, namely entrepreneur gender and experience, team size, equity offering, target amount, percentage of female, sophisticated, and high net investors, and percentage of investors from the UK.

As seen from Table 2, five covariates are statistically significant at 0.05 significance level. The sign of the corresponding regression coefficient estimates dictate the directionality of significant covariate effects on the campaign outcome. More specifically, on the one hand skilled leading entrepreneurs, bigger entrepreneur teams, and a higher percentage of sophisticated investors are all beneficial to a campaign's outcome. On the other hand, lower equity offerings indicate less risk and male investors tend to choose projects that will get funded. Although the percentage of successful female entrepreneurs is higher than that of men, the saturated logistic regression model does not show that the entrepreneur's gender is a significant predictor of a campaign's outcome.

In a second model, we keep only the five significant predictors of campaign success to build a more parsimonious logistic regression model. Table 2 displays the p-values, regression coefficients, and associated $95 \%$ confidence intervals for this simpler model. Statistical significance is preserved for all five covariates and covariate effects, as depicted by coefficient estimates, appear amplified. Partly due to the simplicity of the fitted logit model and because of the varying number of missing data among subsets of covariates, we didn't pursue more systematic model selection. Our main interest has been placed on data mining to extrapolate preliminary signals of differentiated activity between male and female investors and entrepreneurs in the data set. We searched for possible interactions between the five significant covariates. For instance, we checked whether bigger teams led by more experienced entrepreneurs have a combined positive effect on campaign success, and it turned out that this is not the case.

The performance of the logistic regression models is rather low (McFadden's pseudo $R^{2}$ is .125 for the saturated model and .121 for the parsimonious model). This emphasizes the relative lack of prescriptiveness of this first investigation into an unexplored topic and calls for further studies that incorporate more detailed data for validation.

The fact that the percentage of female investors is a significant negative predictor of campaign success does not imply causality. In fact, there are at least two possible confounders. First, it might be that the underlying project category or venture sector is the true causal predictor. For example, technology-oriented campaigns might be by default more prone to success and at the same time more popular in male investor circles. To perform a first test along this lead, we look at the classification of campaigns into categories. The platform provides a predefined set of categories that are used by entrepreneurs to label their campaigns to indicate market sector. This information is available for a subset of the campaigns. Using this data, we rank categories based on the difference in interest that they generate for male and female investors. As shown in Figure 4, for instance 1.72\% of both male and female investors are drawn to the 'Education' category. There are a few other categories that are preferred by a comparable percentage of the two investor groups. However, campaigns in 'Food \& Drink', 'Health' and 'Consumer Products' are attractive to a higher percentage of the female than male investors. On the contrary, 'Finance', 'E-Commerce \& Markets' and 'IT \& Telecom' draw interest from a higher percentage of men.

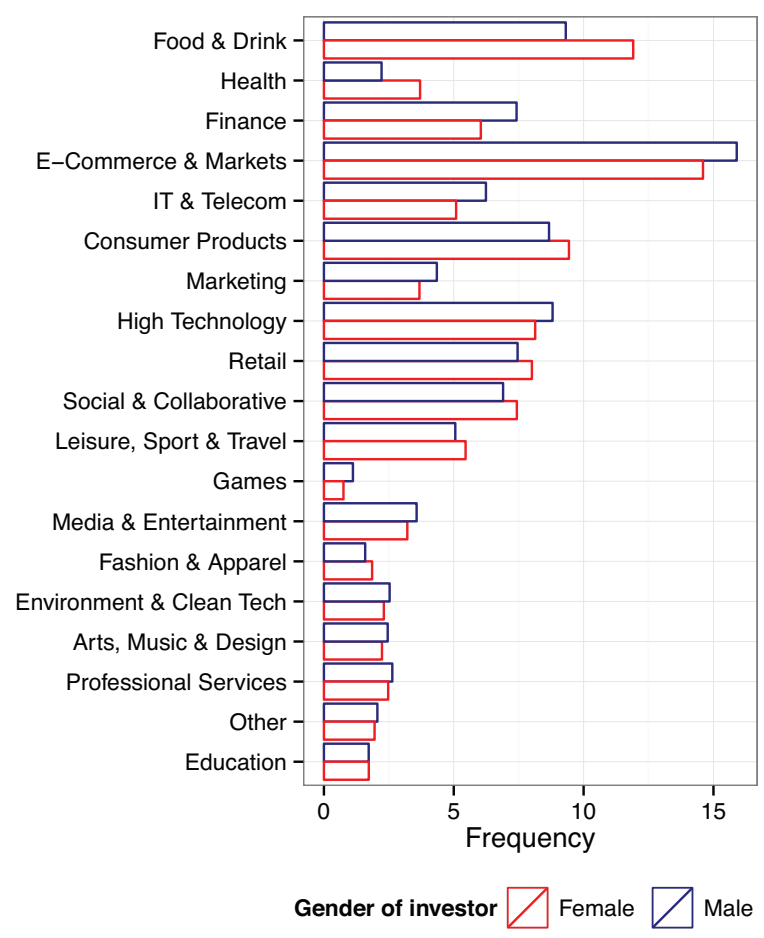

Figure 4: Categories of successful campaigns with frequencies showing how often male and female investors choose a campaign with the specific category label. Note that a single campaign can be assigned to multiple categories

Second, homophily between investors and entrepreneurs or gender-specific herding (Mohammadi and Shafi 2017) among investors might also explain away the higher success of campaigns supported mainly by male investors. Since the total number of male investors is higher on the site, the possibility of higher homophily impact among men cannot be precluded in advance. Our final piece of analysis takes a first look at this issue.

Gender-homophily between investors and entrepreneurs Within a network analytic framework, we evaluate genderhomophily given the structure of the entrepreneur-investor graph. Specifically, we ask How likely is it that investments are made between users of the same gender given the number of female and male users as well as the number of investments users receive or place? To compute this probability, we generate a set of possible graphs that could represent the transactions occurred on the platform. The created graphs maintain the key structural features of the entrepreneur- 


\begin{tabular}{|c|c|c|c|c|c|c|}
\hline & \multicolumn{6}{|c|}{ Models } \\
\hline & \multicolumn{3}{|c|}{ Saturated model } & \multicolumn{3}{|c|}{ Parsimonious model } \\
\hline & $\hat{\theta}$ & C.I. & $\mathrm{p}$ & $\hat{\theta}$ & C.I. & $\mathrm{p}$ \\
\hline \multicolumn{7}{|l|}{ Entrepreneur-side covariates } \\
\hline Female entrepreneur & 0.416 & $\begin{array}{r}0.926 \\
-0.099\end{array}$ & $1.10 \mathrm{e}-01$ & & & \\
\hline Entrepreneur experience & 0.455 & $\begin{array}{l}0.712 \\
0.219\end{array}$ & 2.91e-04 & 0.510 & $\begin{array}{l}0.769 \\
0.271\end{array}$ & $5.96 \mathrm{e}-05$ \\
\hline Team size & 0.198 & $\begin{array}{l}0.303 \\
0.095 \\
\end{array}$ & $1.98 e-04$ & 0.158 & $\begin{array}{l}0.245 \\
0.071 \\
\end{array}$ & 3.60e-04 \\
\hline \multicolumn{7}{|l|}{ Campaign-level covariates } \\
\hline Equity offering $(\%)$ & -0.051 & $\begin{array}{l}-0.023 \\
-0.080\end{array}$ & $4.19 \mathrm{e}-04$ & -0.057 & $\begin{array}{l}-0.031 \\
-0.084\end{array}$ & $2.35 e-05$ \\
\hline Target amount ${ }^{\dagger}$ & -0.184 & $\begin{array}{r}0.010 \\
-0.382 \\
\end{array}$ & $6.55 e-02$ & & & \\
\hline \multicolumn{7}{|l|}{ Investor-side covariates } \\
\hline Female investors $(\%)$ & -3.251 & $\begin{array}{l}-1.730 \\
-4.942\end{array}$ & $7.16 e-05$ & -3.056 & $\begin{array}{l}-1.609 \\
-4.656\end{array}$ & $8.29 \mathrm{e}-05$ \\
\hline Sophisticated investors (\%) & 2.319 & $\begin{array}{l}4.325 \\
0.451\end{array}$ & $1.78 \mathrm{e}-02$ & 2.540 & $\begin{array}{l}4.542 \\
0.687\end{array}$ & $9.53 e-03$ \\
\hline High net worth investors (\%) & 0.133 & $\begin{array}{r}1.320 \\
-1.104\end{array}$ & $8.28 \mathrm{e}-01$ & & & \\
\hline UK investors (\%) & 0.279 & $\begin{array}{r}1.369 \\
-0.765\end{array}$ & $6.07 \mathrm{e}-01$ & & & \\
\hline
\end{tabular}

$\dagger$ This covariate is logged

Table 2: Results of logistic regression models that predict campaign success based on covariates listed in Table 1. Here we summarize estimated regression coefficients, confidence intervals, and p-values for the two models. Bold typesetting indicates statistical significance at the $p<.05$ level

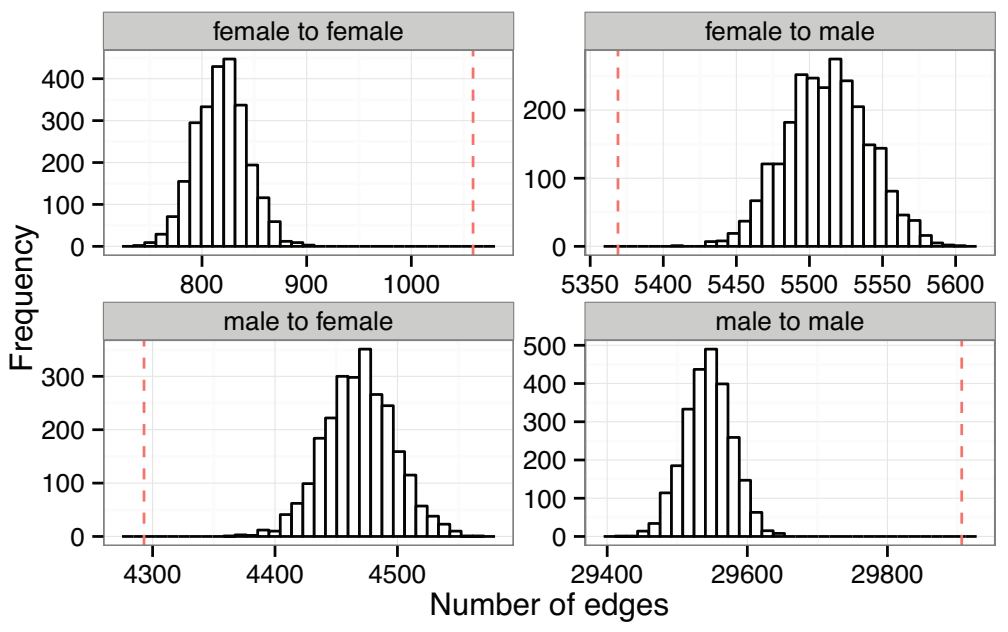

Figure 5: Expected number of investments conditional on investor and entrepreneur gender given key features of the network structure (i.e., number of male and female investors and entrepreneurs as well as prevalence of high and low activity entrepreneurs and investors). Comparing the expectation with patterns in the observed network helps us to understand whether the social process of homophily underlies investment behavior

investor network, but are oblivious to the gender of the users. By comparing gender-related patterns in the observed net- work data with expectations that arise from the randomized graphs, we can assess statistically whether homophily 
is more predominant than expected by chance under certain structural constraints. We use an edge swap procedure to generate random graphs with fixed degree sequence (Gotelli and Graves 1996; Shen-Orr et al. 2002; Gionis et al. 2007; Newman 2010) as implemented in the igraph $\mathrm{R}$ package (Csárdi and Nepusz 2006).

Figure 5 shows the number of edges between users of specific genders from 2,500 random graphs obtained with edge swapping. The numbers of edges in the observed data set are not expected based on the distributions generated from the random sample. Regarding the tendency for forming samegender entrepreneur-investor ties, homophily is much more likely than expected based on the network structure both for women and men. In both cases the unexpectedness is highly significant $(\mathrm{p} \leq .0004)$. Conversely, investors and entrepreneurs of opposite gender are significantly less likely to connect $(\mathrm{p} \leq .0004)$. Note that using a less realistic random graph model that preserves only the number of entrepreneurs and investors as well as the density of the network, homophily does not appear to be significant. This indicates that the gender-specific degree distributions are important on both the entrepreneur and investor side.

\section{Conclusions and Discussion}

This paper investigates gender-related patterns of entrepreneurship and investment on a leading UK-based equity crowdfunding platform. We present evidence of gender differences in participation. Our results suggest that campaigns led by female entrepreneurs are slightly more successful than male-led campaigns. Furthermore, despite the strong gender-homophily on the platform, campaigns with a higher participation rate from female investors tend to fail at raising the target amount. Although our study is unique in its proposition and data usage, the results of our regression models require careful interpretation and further validation.

Previous research has shown that women are more risk averse than men, especially in financial matters (Sundén and Surette 1998; Eckel and Grossman 2002; Holt and Laury 2002; Croson and Gneezy 2009). Equity crowdfunding entails a considerably higher risk than traditional financial settings, and thus not only is risk aversion likely to deter women from investing in high-risk, high-return ventures, but it might also reduce their willingness to engage in crowdfunding altogether. Our models indicate that more skilled entrepreneurs and larger teams have significantly higher chances of fundraising success and so are campaigns with lower equity offering. More transparency about these findings related to characteristics of fund-seekers and campaigns can help investors to overcome some of the barriers they face throughout the decision-making process. For instance, a website design or an investor support tool which highlights entrepreneur experience, team size, age of the fund-seeking firm, and previous fund-raising success could assist cautious female investors with more accurate risk-assessment. Moreover, tools that focus on team qualifications and venture merits instead of entrepreneur gender per se would also benefit female entrepreneurs in a crowdsourcing context where it is unclear how salient gender is and how much it matters in obtaining funds.
Our study has several limitations that open up avenues for future research. Most importantly, it is based on a single equity crowdfunding platform. While the results are statistically significant in case of the studied equity crowdfunding platform, generalization is difficult in the lack of further supporting evidence from other settings. Next, our work is limited due to the nature of aggregated observed variables and unobservable preferences. For example, we do not have detailed information about the entrepreneur teams in terms of gender and skill composition. Additionally, we know very little about the campaigns themselves. In consequence, we cannot exclude the possibility that female investors are interested in funding businesses that serve the social good. To clarify these issues, our study would benefit from a combination of the currently deployed data mining approaches with field experiments that could shed light on the signal-to-noise ratio of the observed covariates and might provide essential information that is not being logged by the platform so far. Since these details are not visible to the investor crowd either, we expect most of our results to hold up in case such scrutiny becomes possible. Finally, it is unclear how the algorithmic choices made by the platform in displaying content on their platform impact the visibility, popularity and ultimate success of campaigns. Appropriate experimental tests and/or activity logs on their platform would help to disentangle the effects of platform design.

Despite these limitations, our findings reveal interesting insights related to gender differences, which help tackling the puzzling task of inferring campaign success on crowdfunding platforms. Such indicators of campaign success provide benefits to entrepreneurs, who can retract their application and avoid the negative impact of a failed project, as well as investors, who can use this as a predictive tool for reinvesting. Our results thus inform and broaden the building field of crowd-aware system design in equity crowdfunding and beyond.

\section{Acknowledgments}

The authors are grateful to the company for sharing their unique data set. The Data Science team has provided indispensable information at various stages of this work. We also appreciate the useful input we received from the anonymous reviewers and from Ancsa Hannák.

\section{References}

Ahlers, G. K.; Cumming, D.; Günther, C.; and Schweizer, D. 2015. Signaling in equity crowdfunding. Entrepreneurship Theory and Practice 39(4):955-980.

Alesina, A. F.; Lotti, F.; and Mistrulli, P. E. 2013. Do women pay more for credit? Evidence from Italy. Journal of the European Economic Association 11:45-66.

Althoff, T.; Danescu-Niculescu-Mizil, C.; and Jurafsky, D. 2014. How to ask for a favor: A case study on the success of altruistic requests. ICWSM 2014.

Barasinska, N., and Schaefer, D. 2014. Is crowdfunding different? Evidence on the relation between gender and funding success from a German peer-to-peer lending platform. German Economic Review 15(4):436-452. 
Bianchi, S. M.; Robinson, J. P.; and Milkie, M. A. 2006. The Changing Rhythms of American Family Life. Russell Sage Foundation.

Blanchflower, D.; Levine, P.; and Zimmerman, D. 2003. Discrimination in the small-business credit market. The Review of Economics and Statistics 85(4):930-943.

Blau, F., and Kahn, L. 2000. Gender differences in pay. NBER Working Papers 7732, National Bureau of Economic Research, Inc.

Brooks, A. W.; Huang, L.; Kearney, S. W.; and Murray, F. E. 2014. Investors prefer entrepreneurial ventures pitched by attractive men. Proceedings of the National Academy of Sciences 111(12):4427-4431.

Brush, C.; Carter, N. M.; Gatewood, E. J.; Greene, P. G.; and Hart, M. 2008. The Diana project: Women business owners and equity capital: The myths dispelled. Babson College Center for Entrepreneurship research paper no. 2009-11.

Bryant, S. L.; Forte, A.; and Bruckman, A. 2005. Becoming wikipedian: Transformation of participation in a collaborative online encyclopedia. In Proceedings of the 2005 International ACM SIGGROUP Conference on Supporting Group Work, GROUP '05, 1-10. New York, NY, USA: ACM.

Ceyhan, S.; Shi, X.; and Leskovec, J. 2011. Dynamics of bidding in a P2P lending service: Effects of herding and predicting loan success. In Proceedings of the 20th International Conference on World Wide Web, WWW '11, 547-556. New York, NY, USA: ACM.

Chaganti, R.; DeCarolis, D.; and Deeds, D. 1995. Predictors of capital structure in small ventures. Entrepreneurship: Theory and Practice 20(2):7-18.

Coleman, S., and Robb, A. 2009. A comparison of new firm financing by gender: Evidence from the Kauffman Firm Survey data. Small Business Economics 33(4):397.

Cooper, S.; Khatib, F.; Treuille, A.; Barbero, J.; Lee, J.; Beenen, M.; Leaver-Fay, A.; Baker, D.; Popovic, Z.; and Players, F. 2010. Predicting protein structures with a multiplayer online game. Nature 466(7307):756-760.

Croson, R., and Gneezy, U. 2009. Gender differences in preferences. Journal of Economic Literature 47(2):448-74.

Csárdi, G., and Nepusz, T. 2006. The igraph software package for complex network research. InterJournal Complex Systems:1695.

Cumming, D., and Dai, N. 2010. Local bias in venture capital investments. Journal of Empirical Finance 17(3):362380.

Dorfleitner, G.; Leidl, M.; Priberny, C.; and von Mosch, J. 2013. What determines microcredit interest rates? Applied Financial Economics 23(20):1579-1597.

Duarte, J.; Siegel, S.; and Young, L. 2012. Trust and credit: The role of appearance in peer-to-peer lending. Review of Financial Studies 25(8):2455-2484.

Eckel, C. C., and Grossman, P. J. 2002. Sex differences and statistical stereotyping in attitudes toward financial risk. Evolution and Human Behavior 23(4):281-295.
Freedman, S., and Jin, G. Z. 2008. Do social networks solve information problems for peer-to-peer lending? Evidence from prosper.com. NET Institute working paper no. 08-43.

Gionis, A.; Mannila, H.; Mielikäinen, T.; and Tsaparas, P. 2007. Assessing data mining results via swap randomization. ACM Trans. Knowl. Discov. Data 1(3).

Gompers, P., and Lerner, J. 2004. The venture capital cycle. MIT Press.

Gorbatai, A., and Nelson, L. 2015. Gender and the language of crowdfunding. Available at SSRN: https://ssrn.com/abstract=2549354.

Gotelli, N. J., and Graves, G. R. 1996. Null models in ecology. Smithsonian Institution Press.

Greenberg, J., and Mollick, E. 2016. Activist choice homophily and the crowdfunding of female founders. Administrative Science Quarterly.

Greenberg, M. D.; Pardo, B.; Hariharan, K.; and Gerber, E. 2013. Crowdfunding support tools: Predicting success \& failure. In $\mathrm{CHI}$ ' 13 Extended Abstracts on Human Factors in Computing Systems, CHI EA '13, 1815-1820. New York, NY, USA: ACM.

Hargittai, E., and Shaw, A. 2015. Mind the skills gap: the role of internet know-how and gender in differentiated contributions to Wikipedia. Information Communication and Society 18(4):424-442.

Hargittai, E. 2010. Digital na(t)ives? Variation in Internet skills and uses among members of the "net generation". Sociological Inquiry 92-113.

Holt, C. A., and Laury, S. K. 2002. Risk aversion and incentive effects. American Economic Review 92(5):1644-1655.

Horvát, E.-A.; Uparna, J.; and Uzzi, B. 2015. Network vs market relations: The effect of friends in crowdfunding. In Proceedings of the 2015 IEEE/ACM International Conference on Advances in Social Networks Analysis and Mining 2015, ASONAM '15, 226-233. New York, NY, USA: ACM.

Iyer, R.; Khwaja, A. I.; Luttmer, E. F. P.; and Shue, K. 2009. Screening in new credit markets: Can individual lenders infer borrower creditworthiness in peer-to-peer lending? Afa 2011 denver meetings paper.

Jeppesen, L. B., and Lakhani, K. R. 2010. Marginality and problem-solving effectiveness in broadcast search. Organization Science 21(5):1016-1033.

Kanze, D.; Huang, L.; Conley, M. A.; and Higgins, E. T. 2017. We ask men to win and women not to lose: Closing the gender gap in startup funding. Academy of Management Journal.

Karimi, F.; Wagner, C.; Lemmerich, F.; Jadidi, M.; and Strohmaier, M. 2016. Inferring gender from names on the web: A comparative evaluation of gender detection methods. In Proceedings of the 25th International Conference Companion on World Wide Web, WWW' 16 Companion, 53-54. Republic and Canton of Geneva, Switzerland: International World Wide Web Conferences Steering Committee.

Kolaczyk, E. D. 2009. Statistical Analysis of Network 
Data: Methods and Models (Springer Series in Statistics). Springer.

Leland, H. E., and Pyle, D. H. 1977. Informational asymmetries, financial structure, and financial intermediation. The Journal of Finance 32(2):371-387.

Liu, W., and Ruths, D. 2013. Whats in a name? Using first names as features for gender inference in twitter. In $A A A I$ Spring Symposium Series.

Lutter, M. 2015. Do women suffer from network closure? the moderating effect of social capital on gender inequality in a project-based labor market, 1929 to 2010. American Sociological Review 80(2):329-358.

Mandel, H. 2013. Up the down staircase: Women's upward mobility and the wage penalty for occupational feminization, 1970-2007. Social Forces 91(4):1183.

Marom, D.; Robb, A.; and Sade, O. 2016. Gender dynamics in crowdfunding (kickstarter): Evidence on entrepreneurs, investors, deals and taste-based discrimination. Available at SSRN: https://ssrn.com/abstract=2442954.

Matei, S. A., and Britt, B. The $1 \%$ effect. (forthcoming).

McCaughey, M., and Ayers, M. D., eds. 2003. Cyberactivism: Online Activism in Theory and Practice. Bristol, PA, USA: Taylor \& Francis, Inc.

Mohammadi, A., and Shafi, K. 2017. Gender differences in the contribution patterns of equity-crowdfunding investors. Small Business Economics 1-13.

Mollick, E. 2014. The dynamics of crowdfunding: An exploratory study. Journal of Business Venturing 29(1):1 - 16.

Newman, M. 2010. Networks: An Introduction. Oxford University Press, 1st edition.

Page, S. E. 2007. Prologue to the difference: How the power of diversity creates better groups, firms, schools, and societies. In The Difference: How the Power of Diversity Creates Better Groups, Firms, Schools, and Societies. Princeton University Press.

Ravina, E. 2012. Love \& loans: The effect of beauty and personal characteristics in credit markets. Working Paper, Columbia Business School Finance and Economics.

Robles, G.; Arjona Reina, L.; Serebrenik, A.; Vasilescu, B.; and González-Barahona, J. M. 2014. Floss 2013: A survey dataset about free software contributors: Challenges for curating, sharing, and combining. In Proceedings of the 11th Working Conference on Mining Software Repositories, MSR 2014, 396-399.

Sauermann, H., and Franzoni, C. 2015. Crowd science user contribution patterns and their implications. Proceedings of the National Academy of Sciences 112(3):679-684.

Shen-Orr, S. S.; Milo, R.; Mangan, S.; and Alon, U. 2002. Network motifs in the transcriptional regulation network of Escherichia coli. Nature Genetics 31:1061-4036.

Social Security Administration. Baby names from social security card applications-National level data. https://catalog.data.gov/dataset/baby- \\names-fromsocial-security-card- $\backslash \backslash$ applications-national-level-data. Accessed: 2017-08-15.
Sundén, A. E., and Surette, B. J. 1998. Gender differences in the allocation of assets in retirement savings plans. The American Economic Review 88(2):207-211.

Uzzi, B. 1999. Embeddedness in the making of financial capital: How social relations and networks benefit firms seeking financing. American Sociological Review 64(4):481-505.

van Knippenberg, D.; Dreu, C. K. W. D.; and Homan, A. C. 2004. Work group diversity and group performance: An integrative model and research agenda. Journal of Applied Psychology 89(6):1008-1022.

Vasilescu, B.; Posnett, D.; Ray, B.; van den Brand, M. G.; Serebrenik, A.; Devanbu, P.; and Filkov, V. 2015. Gender and tenure diversity in github teams. In Proceedings of the 33rd Annual ACM Conference on Human Factors in Computing Systems, CHI '15, 3789-3798.

Vismara, S. 2016. Equity retention and social network theory in equity crowdfunding. Small Business Economics 46(4):579-590.

Vulkan, N.; Astebro, T. B.; and Sierra, M. F. 2016. Equity crowdfunding: A new phenomena. Journal of Business Venturing Insights 5:37-49.

Wachs, J.; Hannák, A.; Vörös, A.; and Daróczy, B. 2017. Why do men get more attention? Exploring factors behind success in an online design community. ICWSM 2017.

Weber, S. 2004. The Success of Open Source. Cambridge, MA, USA: Harvard University Press.

Zhang, J. 2011. The advantage of experienced start-up founders in venture capital acquisition: evidence from serial entrepreneurs. Small Business Economics 36(2):187-208. 